\title{
Perspectives of Education in Diabetes
}

\author{
Freddy Contreras ${ }^{1}$ and Manuel Velasco ${ }^{2 *}$ \\ ${ }^{1}$ Freddy Contreras, Associate Professor of Pathophysiology, Nursing School, Faculty of Medicine, Central University of Venezuela, Caracas, Venezuela, South \\ America
}

${ }^{2}$ Manuel Velasco, Professor of Pharmacology, Vargas Medical School, Central University of Venezuela, Caracas, Venezuela, South America

*Corresponding author: Manuel Velasco, Professor of Pharmacology, Vargas Medical School, Central University of Venezuela, Caracas, Venezuela, South America

Submission: 眥 February 26, 2018; Published: 海 April 09, 2018

\section{Editorial}

Diabetes Mellitus (DM) is a chronic disease that is a public health problem worldwide due to its prevalence, and mortality and complications that arise and consequently the high costs for both the patient, his family, the society and therefore for the state [1]. In accordance with the statement by Joslin E [2-4] when he said "Education is not a part of the treatment of diabetes, it is the treatment" and "The diabetic who knows the most is the one who lives the most" and given that Diabetes education is one of the fundamental pillars to achieve the short and medium term objectives and in virtue that any member of the health team can fulfill this role, it is necessary to give relevance to education in DM as a therapeutic strategy of high value.

The treatment for DM is suggested and applied by a multidisciplinary team specialized in the care of patients with diabetes, this group consists essentially of doctors, nutritionists, nurses, educators, psychologists and podiatrists. The treatment also depends on several components, which have to work in a cohesive way to obtain better results, namely: feeding plan; pharmacological treatment (AO-Insulin); exercise; self-control and education.

The objectives of the treatment are aimed at controlling glycaemia, avoiding and or reducing acute and chronic complications, maintaining the patient asymptomatic, greater adherence to treatment and improving the quality of life through psychosocial well-being. We can then redefine Diabetes as a chronic disease that requires continuous medical attention, support and education of the patient for self-control, in order to prevent acute complications and reduce the risk of long-term complications [5].

In the medical literature, numerous studies [6-12] have shown that therapeutic education significantly influences to achieve better control of Diabetes and thus avoid, prevent or delay complications, evidencing unavoidable benefits not only in metabolic and clinical parameters but also in psychosocial aspects. With the publication of the results of the Diabetes Control and Complications Trial, DCCT [13] and in DM2 the UK Prospective Diabetes Study, UKPDS [14]; in which it is emphasized that intensive therapy required greater focus of the patient in everything related to self-control, it was possible to change the focus in the care of the patient with diabetes, which went from being specific measurements of both glycemia and blood pressure to the prevention of complications and intensification of treatment with well-defined metabolic objectives and strict compliance.

In this sense, once the patient is diagnosed the multidisciplinary team of health professionals with a perspective in diabetes education, should set goals regarding the normalization of blood glucose levels, knowledge acquisition and effective self-management; in order to achieve this, it must set very well defined objectives in the short and long term. That is why it is imperative that all providers of care in DM must be trained in diabetes education, as an optimal strategy to effectively and efficiently manage the goals of metabolic control, greater adherence and quality of life, the ultimate goal of treatment.

That is why the health professional at any level of care should emphasize the need to use therapeutic education as a crucial tool to provide the person with DM, and the family, knowledge, skills and abilities [15]. Which result in the acquisition of positive behaviors, healthy and satisfactory alternatives for the care of this clinical condition and finally improve the quality of life.

\section{References}

1. Montilla M, Mena LN, López De, Andrés A (2012) Efectividad de la Educación Diabetológica Sistematizada en niños que debutan con Diabetes Mellitus tipo 1, Index Enferm 21(1-2): 15-20.

2. Joslin EP (1998) Diabetic Manual for the Doctor and patient 1918a centennial portrait-Joslin Diabetes Center.

3. A History of Elliott P. Joslin, MD, Founder, Joslin Diabetes Center.

4. Barnett DM, Joslin Elliot Proctor (1999) American National Biography. Oxford Press, North Carolina, USA, pp. 282-283.

5. American Diabetes Association (2013) Standards of Medical Care in Diabetes. Diabetes Care 36(1): S11-S66.

6. Barlow JH, Wrighht C. Sheasby J, Turner A, Hainsworth J (2002) Selfmanagement approaches for people with chronic conditions: a review. Patient Educ Couns 48(2): 177-187.

7. Brown SA (1999) Interventions to promote Diabetes self-Management state of the science. Diabetes Educator 25(6): 52-61.

8. Malinda Peeples, Janice Koshinsky, Janis McWilliams (2007) Beneficios de la educación diabética: mejores resultados sanitarios mediante un buen control personal. Diabetes Voice 52: 5-8. 
9. Rodríguez LM, Hassan KV, Rhodes J, McKay SV, Heptulla RA (2013) The Relationship between Self-Management and Glycemic Control in a Cohort of Children with Type 1 and Type 2 Diabetes. J Diabetes Metab $4: 319$.

10. The look AHED Research Group (2006) The Look Ahead Study: A description of the Lifestyle Intervention and the evidence supporting it. Obesity 14(5): 737-751.

11. Armengol E, Losada W (2010) Desarrollo de un programa educativo estructurado en diabetes para pacientes pediátricos. Av Diabetol 26: 203-207.

12. Gagliardino JJ, Etchegoyen G (2001) A model educational program for people with type 2 diabetes: a cooperative Latin American implementation study (PENDNID-LA). Diabetes Care 24(6): 1001-1007.

13. DCCT Research Group (1993) The effect of intensive treatment of diabetes on the development and progression of long-term complications in insulin dependent diabetes mellitus. N Engl J Med 329: 977-978.

14. Paromita K, Ian P, Richard D (1999) The UK Prospective Diabetes Study (UKPDS): clinical and therapeutic implications for type 2 diabetes. $\mathrm{Br} J$ Clin Pharmacol 48(5): 643-648.

15. Contreras F, Sánchez M, Martínez MS, Chávez M, Mindiola A, et al. (2017) Management and Education in Patients with Diabetes Mellitus. Med Clin Rev 3: 2-7.

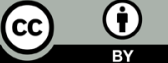

Creative Commons Attribution 4.0 International License

For possible submissions Click Here

\section{Submit Article}

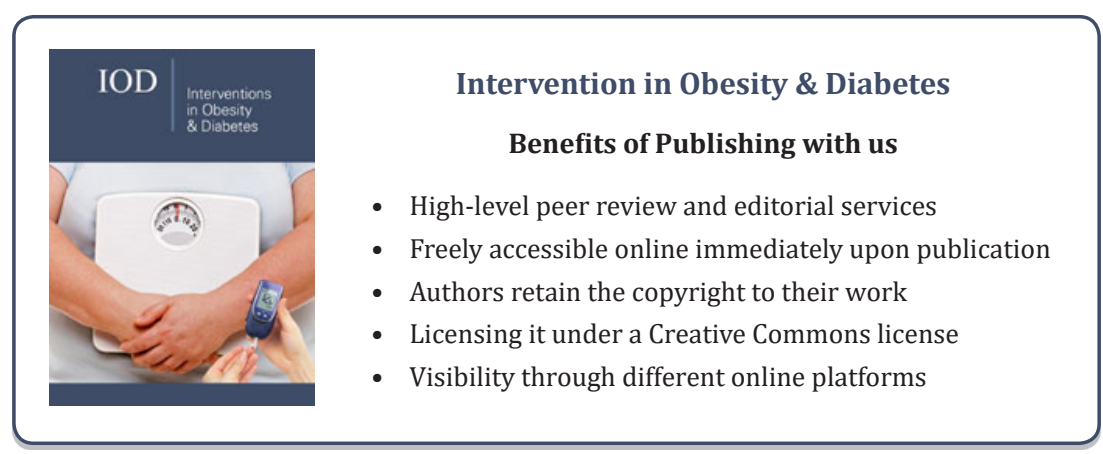

